\title{
UMA ANÁLISE CONSTITUCIONAL DO DIREITO DE AÇÃO NO PROCESSO CIVIL BRASILEIRO*
}

\section{A CONSTITUTIONAL ANALYSIS OF THE RIGHT OF ACTION IN THE BRAZILIAN CIVIL SUIT}

\author{
Márcia Regina Pitta Lopes Aquino
}

\begin{abstract}
Resumo: O estudo objetiva a análise do direito de ação no processo civil brasileiro a partir da Constituição Federal. Aponta a crise por que passam Estado, Direito e Ciência Jurídica ,especialmente após a Segunda Guerra Mundial. Procedimentalismo e substancialismo, bem como jusnaturalismo e positivismo jurídico são apresentados em seus pontos fundamentais. Com fundamento em teorias que compõem uma "terceira via", busca demonstrar a importância dos procedimentos na realização dos valores consubstanciados em princípios constitucionais que se irradiam por todo o ordenamento jurídico. Conclui que o processo não é apenas um instrumento, mas uma dimensão do direito. $\mathrm{O}$ direito de ação expresso no artigo $5^{\underline{a}}$, XXXV da Constituição Federal é eminentemente processual e deve ser entendido como direito ao processo.
\end{abstract}

Palavras-chave: Constituição. Princípios. Procedimento Direito de ação.

Abstract: The purpose of this study is to analyze the right of action in the Brazilian Civil Suit according to the Federal Constitution. This research highlights the crisis that the State, the Law and the Juridical Science have gone through go mainly after World War II. Proceduralism and substantialism are addressed in regard to their fundamental aspects as well as the existent dilemma between juridical positivism and jusnaturalism. Based on the theories that encompass the "third way", this work attempts to show the importance of certain procedures for realizing values of constitutional principles that permeate the whole juridical order. It is concluded that the process is not only an instrument but also a dimension of law itself. The right of action as expressed in art. 5, Chapter XXXV of the Federal Constitution is eminently procedural and should be undertood as a right to process.

Keywords: Constitucion. Principles. Procedure. Right of action.

"O presente artigo corresponde à síntese de dissertação de mestrado (UEL/2006), elaborada sob a orientação do professor Dr. Marcos Antônio Striquer Soares.

Mestre em Direito Negocial pela Universidade Estadual de Londrina. e-mail: magut@sercomtel.com.br 


\section{INTRODUÇÃO}

A análise constitucional do direito de ação no processo civil brasileiro apresentada neste trabalho tem como ponto de partida a constituição. Não poderia ser diferente: a ênfase é constitucional. Porém, a referência à constituição remete a um outro objeto de estudo: o estado. E este, nas palavras de Pablo Lucas Verdú e Pablo Murillo de la Cueva (1994, p. 113), nasceu e permanece em crise.

Correlata ao desenvolvimento do estado houve sempre uma doutrina coerente que o identificava e explicava em cada fase de seu desenvolvimento. Assim foi a doutrina de Maquiavel, Hobbes e Jean Bodin para o estado moderno que, reagindo à crise política religiosa e socioeconômica daqueles tempos, afirmaram o poder supremo do Estado (VERDÚ; DE LA CUEVA, 1994, p. 114).

Com o constitucionalismo moderno ${ }^{1}$, o estado adquire nova identidade: a constituição limita e organiza o poder do Estado. A primeira forma de estado constitucional é o estado liberal que surge imediatamente após as duas revoluções da segunda metade do século XVIII (americana e francesa). Montesquieu - um de seus grandes teóricos - estrutura a fórmula da "separação de poderes" em que o juiz é apenas a "boca da lei” e o judiciário um poder nulo e invisível. ${ }^{2}$

O estado social nasce no momento em que se busca "superar a contradição entre a igualdade política e a desigualdade social”. Tem preocupações voltadas menos para a liberdade do que para a justiça, como anseio e valor social superior (BONAVIDES, 2004b, p. 185). Todavia, também o estado social se viu diante de uma crise:

a administração constante e ubíqua dos diversos setores da vida em sociedade, levada a cabo para cumprir o programa político que se oferecia como alternativa, termina custando um sacrifício abominável de prerrogativas dos indivíduos, antes garantidas, ainda que mínima e formalmente. (GUERRA FILHO, 2001, p. 80).

${ }^{1}$ Conforme J. J. Gomes Canotilho (2003, p. 51-52), o constitucionalismo moderno, "como o próprio nome indica, pretende opor-se ao chamado constitucionalismo antigo[...]”. Já Karl Loewenstein sustenta que os primeiros a praticar o constitucionalismo foram os hebreus (LOEWENSTEIN, 1970, p. 154). E contrário a esse entendimento Romano (1977, p. 42).

${ }^{2}$ Para alguns autores, porém, o início da fase moderna do constitucionalismo estaria já no século XIII (1215), quando os barões do Reino da Inglaterra impuseram ao rei João Sem Terra a Magna Carta Libertatum. (CANOTILHO, 1990, p. 61; DALLARI, 1995, p. 168). 
No Brasil, desde 1988, vive-se sob uma constituição que nasceu para superar o autoritarismo e o arbítrio. Uma constituição que fundou um estado democrático de direito e que pode, segundo alguns autores, ser entendido como a superação tanto do estado liberal como do estado social. Porém, a distância entre o que determina a constituição e o que vive a sociedade expõe a crise. ${ }^{3}$

A abertura democrática torna oportuno o momento atual para formular novamente a pergunta que Lassale fez em 1862 - O que é a Constituição? - e para, a partir da resposta que se obtiver, buscar entender o direito de ação. É o que se buscará fazer neste trabalho, mas sem a pretensão de apontar solução para a crise instalada. Seria um passo longo demais para alguém de tão pouca estatura. O objetivo é o estudo, a discussão, num contexto de abertura e de possibilidades, e também, de crise não apenas do estado, mas também do Direito e da Ciência Jurídica.

\section{POSITIVISMO E JUSNATURALISMO}

Diz Norberto Bobbio (1995, p. 15-24) que "toda a tradição do pensamento jurídico ocidental é dominada pela distinção entre "direito positivo" e "direito natural”. ${ }^{4}$ A distinção conceitual entre ambos, afirma o autor, já se encontra no pensamento grego. $\mathrm{O}$ nascimento do positivismo jurídico ocorre quando não mais se considera direito positivo e direito natural no mesmo sentido, vale dizer, quando se reduz todo o direito ao direito positivo. Define-se, portanto, como positivismo jurídico a "doutrina segundo a qual não existe outro direito senão o positivo”. Sua origem está na formação do Estado moderno quando este concentra em si todos os poderes, e, em primeiro lugar, o de criar o direito (BOBBIO, 1995, p. 25-6).

Todavia, a pergunta sobre o indisponível do direito, isto é, "saber se o homem pode dispor livremente do Direito ou se lhe são impostos limites na criação do

${ }^{3}$ No Brasil, segundo Lenio Luiz Streck, a crise do Direito é apresentada "sob feição particular, vale dizer, como crise do Poder Judiciário”. (STRECK, 2004, p. 1).

Sobre a crise do poder judiciário no Brasil, Grinover (1991, p. 18-26) e Camon de Passos (2003, p. 105 -117).

${ }^{4}$ Expõe Luiz Roberto Barroso: "o positivismo filosófico foi fruto de uma crença exacerbada no poder do conhecimento científico. Sua importação para o Direito resultou no positivismo jurídico, na pretensão de criar-se uma ciência jurídica, com características análogas às ciências exatas e naturais. A busca de objetividade científica, com ênfase na realidade observável e não na especulação filosófica, apartou o Direito da moral e dos valores transcendentes. Direito é norma, ato emanado do Estado com caráter imperativo e força coativa”. (BARROSO, 2003, p. 290). 
mesmo" mantém-se até os dias de hoje no centro das indagações filosóficas. Por muitos séculos acreditou-se que esse "indisponível" estivesse na natureza, fosse ele chamado de logos, idéia ou essência (KAUFMANN, 2004, p. 31-2).

Se o direito natural da Idade Média era teológico, na Modernidade é um direito secularizado que deveria existir mesmo que Deus não existisse: um direito natural iluminista e racional. Insistia-se na idéia do direito natural "absoluto, universal e supra-histórico, ou seja, vale acima do direito positivo estabelecido pelo homem, vale para todos os homens e vale para todos os tempos”. A determinação do direito justo obtinha-se indagando sobre a natureza do homem e "retirando daí, por dedução lógica, os direitos e deveres naturais do homem". As concepções sobre a natureza do homem também variavam como em Rousseau e Hobbes. A teoria do contrato social desempenha, aí, importante papel (KAUFMANN, 2004, p. 37-8).

O jusnaturalismo moderno, isto é, a crença na "existência de valores e de pretensões humanas legítimas que não decorrem de uma norma emanada do Estado”, foi o trunfo e combustível das revoluções liberais do século XVIII. Porém, ao longo do século XIX, com a consolidação dos ideais constitucionais em textos escritos e com o êxito do movimento de codificação, o jusnaturalismo alcança seu apogeu e, paradoxalmente, inicia-se sua superação. Considerado metafísico e anticientífico, é empurrado para a margem da história (BARROSO, 2003, p. 289).

O século XIX situa-se, assim, sob o signo do positivismo jurídico. Sobre direito natural poucos falavam. No decurso desse mesmo século desenvolveu-se também "a metodologia positivista de Savigny, de acordo com a qual o juiz apenas tem de 'subsumir', isto é, articular duas grandezas objetivas, a lei e o caso, devendo ele próprio manter-se totalmente à margem de tal processo [...].” (KAUFMANN, 2004, p. 45).

O grande lastro metodológico do século XX foi o formalismo e o positivismo (CORDEIRO, 2002, p. xiii, xvi). No âmbito constitucional, os positivistas são os 'Mestres da preservação da juridicidade dos textos constitucionais'. A constituição do positivismo jurídico-estatal é nomeadamente formalista e fechada. Nela a norma se explica pelo seu conteúdo nominal, por sua rigidez, vazada por escrito, hermética em presença da realidade exterior (BONAVIDES, 2004a, p. 171).

Conforme Antonio Menezes Cordeiro (2002, p. xvi-xxii), várias são as críticas endereçadas ao positivismo e ao formalismo fundamentadas, quanto ao útlimo, na natureza histórico-cultural do Direito e na sua incapacidade perante a riqueza dos casos concretos. Em relação ao positivismo, as críticas referem-se: a sua insistência em negar lacunas e em não ter meios para lidar com conceitos 
indeterminados; a sua inoperabilidade em situações de contradições de princípios; e, finalmente, a sua incapacidade de apontar soluções perante injustiças ou inconveniências graves no Direito vigente.

Tais críticas já podem demonstrar porque o positivismo e o formalismo jurídico sucumbiram juntamente com as vítimas do Holocausto durante a Segunda Guerra Mundial. Todavia, não só o positivismo - degenerado num puro positivismo legalista foi abatido - "também se abusou da idéia do direito natural, ao recusar aplicação a leis vigentes em nome dum direito natural étnico" (KAUFMANN, 2004, p. 45).

Após a Segunda Guerra Mundial, houve um renascimento do direito natural "menos por seus méritos intrínsecos, do que pela flagrante contradição da neutralidade axiológica do positivismo frente ao terrorismo do $3^{\underline{a}}$ Reich" (GUERRA FILHO, 2002, p. 110). Tal renascimento foi passageiro, dele restando apenas uma negação à possibilidade de decisões judiciais monstruosas.

Diz Arthur Kaufmann: "o que nos aflige é a limitação da arbitrariedade na feitura e aplicação da lei. Para tal não existe uma resposta satisfatória, enquanto se insistir na alternativa: ou direito natural ou positivismo, tertium non datur" (KAUFMANN, 2004, p. 49). ${ }^{5} \mathrm{Na}$ tentativa de superação deste dilema surgem diversas teorias que podem ser agrupadas sob o rótulo de “terceira via”. Entre elas estão: a filosofia do direito de Gustav Radbruch, a hermenêutica jurídica, a teoria da argumentação jurídica, a teoria dos princípios gerais de direito e o CLS (Critical Legal Studies).

É possível afirmar, portanto, que também a Ciência jurídica passa por uma crise. Na complexidade da sociedade atual, conceitos como soberania popular, representação política, separação de poderes, direitos do homem, controle da constitucionalidade e estado de direito não têm sido capazes de contê-la. Os tribunais constitucionais, em muitas de suas decisões, asseguram a perpetuação de um sistema afastado da realidade social. Surgem, então, conceitos como o de constituição dirigente (Canotilho), que, porém, acabam por se mostrar insuficientes. É necessário, formular novas teorias e, assim, novos conceitos e nova prática política e jurídica que sejam capazes de conter a crise atual. (VERDÚ; DE LA CUEVA, 1994, p. 118-9).

${ }^{5}$ Continua o autor: "há muito que a reflexão sobre esta alternativa conduziu a uma aporia". E aporias "por definição não podem ser solucionadas, permanecendo sempre em aberto, o que não impede que se decida por um modo de resolvê-las, de forma consistente, apresentando os fundamentos da opção por esse e não por outros possíveis modos de solucioná-las”. (GUERRA FILHO, 2002, p. 185). 
No Brasil, a ditadura militar e seu arsenal de violência constituiu grave empecilho para uma "profusão de idéias". Diante da redemocratização, o debate é possível e necessário. Entre os temas a serem revistos, situam-se o papel desempenhado pelo Judiciário e o entendimento que possa fazer a respeito do direito de ação no estado democrático de direito.

\section{JURISDIÇÃO}

É tradicional a referência às doutrinas de Chiovenda e Carnelutti a respeito da jurisdição. Ensina o primeiro (CHIOVENDA, 2002, v. 1, p. 17): "a lei em sentido lato (ou direito objetivo) é a manifestação da vontade coletiva geral, destinada a regular a atividade dos cidadãos ou dos órgãos públicos". O juiz afirma a preexistência da vontade da lei e, portanto, a função jurisdicional não determina nem cria essa vontade (2002, v. 1, p. 60). A jurisdição é, então,

a função do Estado que tem por escopo a atuação da vontade concreta da lei por meio da substituição, pela atividade de órgãos públicos, da atividade de particulares ou de outros órgãos públicos, já no afirmar a existência da vontade da lei, já no torná-la, praticamente, efetiva. (CHIOVENDA, 2002. v. 2, p. 8-9).

É possível concluir que o juiz da doutrina de Chiovenda não se distancia daquele concebido por Montesquieu que deveria apenas ser "a boca que pronuncia as palavras da lei”. À doutrina de Chiovenda associa-se uma concepção dualista do ordenamento jurídico, segundo a qual o direito material é sistema suficiente em si mesmo para a criação de direitos e obrigações. Cândido Rangel Dinamarco - adepto de tal concepção - afirma que a jurisdição "é a função do Estado, destinada à solução imperativa de conflitos e exercida mediante a atuação da vontade do direito em casos concretos" (DINAMARCO, 2002, v. 1, p. 309).

Para Carnelutti, o conceito de lide é fundamental e sua importância na doutrina e legislação brasileira é salientada pela presença de tal conceito na exposição de motivos do Código de Processo Civil: "conflito de interesses qualificado pela pretensão de um dos litigantes e pela resistência do outro" ? Segundo Cândido Rangel Dinamarco (1971, p. 28), a idéia de Carnelutti de que

${ }^{6}$ Os autores referem-se, ainda, a outros conceitos com os quais os juristas tentam superar a atual crise: Estado democrático de direito, sociedade democrática avançada e Estado social de direito. Todavia, há autores que entendem o Estado democrático de direito como superação do Estado liberal e do Estado social entre eles Bonavides (2004).

${ }^{7}$ Exposição de Motivos do Código de Processo Civil , II, n 6 . Se bem que, tenha alterado seu conceito de lide, Carnelutti a define, então, como "conflito (intersubjetivo) 
o escopo do processo é a "justa composição da lide, pressupõe, naturalmente, que as normas jurídicas substanciais contidas na lei não tenham por si sós, aptidão para compô-la” e revela sua concepção unitária do ordenamento jurídico. Afirma, ainda, que, para Carnelutti, o efeito da sentença

é tornar concreto ou particular o preceito abstrato ou genérico contido na norma legal, o comando abstrato é representado por um arco, o qual só se fecha em círculo quando houver o comando complementar; este reside na sentença (não dispositiva) e no negócio jurídico. É, como se vê, uma derivação da teoria de Kelsen. ${ }^{8}$

A breve referência às teorias de Chiovenda e Carnelutti é suficiente para demonstrar que ambas não se afastaram do positivismo. A jurisdição vinculada à lei conforme os ditames do positivismo pressupunha uma sociedade homogênea, na qual os conflitos eram solucionados pelo Judiciário através de simples silogismo. Porém, a sociedade atual não se deixa reger por tal metodologia. Do juiz exige-se mais. A jurisdição no estado democrático de direito não tem como tarefa a simples declaração de vontade legal preexistente, nem mesmo é tão somente a sua individualização para o caso concreto. A atividade jurisdicional deve, diante do caso, concretizar os valores consubstanciados nos princípios constitucionais, que são materiais e processuais, o que revela a fundamental importância dos procedimentos, tanto na atividade jurisdicional como nas demais atividades estatais.

A importância dos procedimentos - não só na atividade jurisdicional - é apresentada por Willis Santiago Guerra Filho ao propor uma disciplina geral a Teoria Geral do Processo - que se refira à administração, à legislação e à jurisdição, pois nos "três casos se tem a necessidade de alcançar uma decisão, que para ser tida como convincente necessita emanar de um processo, do qual participam e discutem os interessados ou representantes desses (GUERRA FILHO, 1990, p. 231-3). ${ }^{9}$

de interesses qualificado por uma pretensão contestada (discutida). [...] Distinguem-se assim, em razão da qualidade da resistência, a lide de pretensão constada e a lide de pretensão insatisfeita”. (CARNELUTTI, 1999, p. 78-81).

${ }^{8}$ Para Kelsen, a sentença também é norma jurídica de natureza constitutiva que resulta da produção escalonada do direito. Tal concepção constitutiva da teoria kelseniana é essencialmente positivista. Da norma fundamental deriva apenas a validade e não o conteúdo da ordem jurídica. "A nenhuma ordem jurídica positiva pode recusar-s a validade por causa do conteúdo das suas normas. é este um elemento essencial do positivismo jurídico". (KELSEN, 1998, p. 242). 


\section{PROCEDIMENTALISMO E SUBSTANCIALISMO}

Ao estudo das constituições e da jurisdição - mormente da jurisdição constitucional - dedicam-se diversos autores cujas concepções podem ser reunidas em dois grupos: procedimentalistas e substancialistas. As primeiras procedimentalistas - estão, em regra, associadas à idéia de legitimação pelo procedimento de Niklas Luhmann, segundo a qual, são os procedimentos que garantem decisões vinculativas e reduzem as complexidades sociais. Pela participação nos procedimentos, os envolvidos aceitam a decisão final. A legitimidade daí decorrente não provém de derivações valorativas ao contrário do que entendem as posições substancialistas (BERCOVICI, 2003, p. 273). Na tese luhmanniana, os tribunais assumem papel fundamental, pois "constituem o centro do sistema jurídico. Tudo mais, inclusive a legislação, representa a periferia” (LUHMANN, 1990, p. 160).

É procedimental a teoria do filósofo alemão Jürgen Habermas para quem a moralidade, a racionalidade e a autonomia do Direito moderno não resultariam do fato de ter-se verificado a positivação de exigências morais nas constituições , mas, sim, da "circunstância de haverem sido instituídos procedimentos para (auto)regulação e o (auto)controle da fundamentação do Direito”. Habermas tece críticas à doutrina da ordem de valores, pois o que faz a constituição é determinar procedimentos políticos, segundo os quais os cidadãos, assumindo seu direito de autodeterminação, podem perseguir cooperativamente o projeto de produzir condições justas de vida (HABERMAS, 2003, p. 242).

9 A importância do processo não só na atividade estatal é salientada por Luiz Fernando Belinetti: "Considera-se, portanto, o processo como o instrumento de que se vale o poder estatal num Estado de direito a fim de construir e aplicar o ordenamento, e não apenas como o instrumento da atividade jurisdicional. [...] os particulares também aplicam cotidianamente o ordenamento na regulação de suas relações jurídicas. A única diferença é que não podem impor coercitivamente a observância do ordenamento, de vez que somente as decisões estatais possuem esse atributo. [...] não vislumbro nenhuma razão para que somente haja processo na atividade estatal. Se fora do Estado também se constrói e aplica o ordenamento, deve também aí haver processo. [...] O poder estatal se expressa através das funções jurisdicional, legislativa e administrativa que o exaurem, valendo-se de instrumentos ideais: os processos". Afirma ainda o autor: "os processos e procedimentos nada mais são, pois, que instrumentos utilizados pelo poder estatal na emissão de decisões que conduzem ao objetivo visado estabelecer regramentos abstratos, administrar interesses públicos e privados e solucionar conflitos jurídicos de interesse”. (BELINETTI, 1994, p. 79-81). 
É justamente de uma ordem de valores presente nas constituições que falam as correntes substancialistas. Tais valores exercem um efeito de irradiação por todo o ordenamento jurídico. Para Lenio Luiz Streck (2004, p. 87) - substancialista - a justiça constitucional deve assumir uma postura intervencionista, desenvolvendo até mesmo, políticas públicas e, além de procedimentos, a constituição instituidora do Estado democrático de direito determina a "realização substantiva dos direitos sociais, de cidadania e aqueles relacionados diretamente à terceira dimensão de direitos”. O Direito, segundo o autor, assume a tarefa de "transformação das estruturas da sociedade".

À Constituição Brasileira de 1988 e ao Estado Democrático de Direito ali inscrito não se adaptam as concepções procedimentalistas puras conforme exposto acima. Há conteúdos materiais que precisam ser concretizados. Todavia, a maneira de realizar tal conteúdo material da constituição, entendido como valores que lhe foram incorporados, deve ser estabelecida considerando-se os mesmos valores.

Robert Alexy, J. J. Gomes Canotilho e Willis Santiago Guerra Filho salientam a importância da presença de princípios e de procedimentos no ordenamento jurídico do Estado democrático de direito. Diante da tentativa de superação do dilema entre direito natural e positivismo jurídico, suas concepções ajustam-se àquelas mencionadas no início deste trabalho e reunidas sob o rótulo de "terceira via”.

Diante da polêmica entre legalismo e constitucionalismo, Robert Alexy (2004, p.160-1), ${ }^{10}$ apresenta a hipótese de um "constitucionalismo moderado" fundamentado numa noção de sistema jurídico composto por normas que podem ser regras ou princípios. Estes são "mandatos de optimización” realizados de acordo com possibilidades fáticas e jurídicas enquanto as regras são "mandatos definitivos”. Para os princípios há ponderação, para as regras, subsunção. O sistema jurídico carece de regras e princípios. ${ }^{11}$

${ }^{10}$ Robert Alexy, explica ainda que, num Estado democrático de direito, como o alemão, distinguem-se duas concepções básicas sobre o sistema jurídico: legalismo e constitucionalismo. A primeira pode ser resumida em quatro fórmulas: norma em vez de valor; subsunção e não ponderação; independência do direito ordinário, em vez de onipresença da constituição e autonomia do legislador democrático dentro do marco da Constituição e, não, onipotência judicial apoiada na constituição. Para a segunda, há na constituição uma ordem objetiva de valores que vale tanto para a legislação como para a administração e jurisdição. Conceitos como dignidade, liberdade e igualdade, Estado de direito, democracia e Estado social proporcionam um conteúdo substancial ao sistema jurídico.

${ }^{11}$ Da mesma forma Canotilho (2003, p. 1162). 
Diz Robert Alexy (2004, p. 162-9): “entre princípios e valores existe uma ampla coincidência estrutural". A diferença está no fato de que, no primeiro caso, decide-se o que é devido, ou seja, o que é ordenado, proibido ou permitido e, no segundo, o que é melhor. A teoria dos princípios, segundo o autor, renuncia a uma intuição dos valores, pois os princípios são normas. Também não conduz a um deslocamento do poder do parlamento aos tribunais, pois não existem apenas princípios materiais, mas também procedimentais. Dessa maneira é que se pode afirmar que Robert Alexy concebe um modelo de sistema jurídico composto por três níveis: regras, princípios e procedimentos: os dois primeiros - regras e princípios - formam seu "lado passivo" e o último - procedimento - o "lado ativo". ${ }^{12}$

Em estudo sobre a relação entre organização/procedimento e direitos fundamentais, a diretriz seguida por J. J. Gomes Canotilho (1990, p. 157-8) (3) $^{13}$ é "existe uma relação recíproca de efeitos ou uma interdependência relacional entre direitos fundamentais (direito material) e procedimento (direito procedimental e processual)". A idéia de procedimento torna-se, desta forma, uma "dimensão intrinsecamente complementadora, integradora e garantidora do direito material”. E acrescenta o autor:

o direito procedimental/processual não é apenas um meio adequado de realização de um direito subjetivo-material preexistente, pois a relação entre direito processual/procedimental não se reduz a uma relação de meio/fim, antes se reconduz a uma relação de integração.

Para Willis Santiago Guerra Filho (1995, p. 256) é “a Constituição , assim como todo o sistema de normas interno ao ordenamento jurídico, um sistema de regras e princípios". Os princípios são "indicadores de uma opção pelo favorecimento de determinado valor” cuja ambiência natural é o texto

${ }^{12}$ Acrescenta-se que, para o autor, sob o conceito amplo de procedimento abarca-se tudo que está sob a fórmula "realización y aseguramiento de los derechos fundamentales a través de la organización y el procedimiento”. (ALEXY, 2002. p. 457-8).

${ }^{13}$ Neste estudo, o autor refere-se a posicionamento de Konrad Hesse apresentado na IV conferência dos Tribunais Constitucionais da Europa realizada em 1978 que também pode ser visto em Hesse (1998, p. 288): "Para poder cumprir a sua função, direitos fundamentais requerem, em primeiro lugar, geralmente em proporção mais ou menos vasta, regulações de organização e procedimento, especialmente claro, por exemplo, na liberdade de associação. [...] Simultaneamente, direitos fundamentais, por sua vez, influem sobre o direito de organização e procedimento que, deste modo, contribui para a realização e asseguramento dos direitos fundamentais.” 
constitucional. Guerra Filho (2002, p. 16-7) justifica essa concepção afirmando o "que se espera hoje de uma constituição são linhas gerais para guiar a atividade estatal e social, no sentido de promover o bem-estar individual e coletivo dos integrantes da comunidade que soberanamente a estabelece".

De acordo com Willis Santiago Guerra Filho (2002, p. 27-9), a constituição tem também natureza de lei processual, assim como os institutos de direito processual possuem estatuto constitucional e são também de natureza material. Não se trata de diferenciar ramos da matéria jurídica ou de uma divisão como a que separa direito público e direito privado. As dimensões - processual e material - são relacionais: conceituam-se uma em função da outra e se exigem mutuamente. ${ }^{14} \mathrm{Na}$ constituição do estado democrático de direito, os procedimentos assumem importância fundamental já que nem princípios nem regras regulam por si mesmos sua aplicação.

\section{AUTONOMIA DO DIREITO PROCESSUAL E O DIREITO DE AÇÃO}

O Direito Processual Civil já foi considerado mero apêndice do Direito Civil. Foi a fase da teoria imanentista ou civilista do direito de ação. ${ }^{15} \mathrm{~A}$ partir da polêmica, ocorrida na Alemanha (1856-1857), entre Bernhard Windscheid e Theodor Müther sobre a actio romana, a doutrina daquele país começou a elaborar a teoria da ação sob novos moldes. Oscar Von Bülow, em 1868 evidenciou, então, a autonomia do direito processual civil mostrando que há também uma

${ }^{14}$ Acrescenta-se que Calmon de Passos faz críticas ao que chama "modismo da instrumentalidade do processo", admitindo que, "antes de o produto condicionar o processo é o processo que condiciona o produto" tanto em nível "macro" como em nível "micro". O autor refere-se às teorias procedimentais e adverte quanto ao uso inadequado do termo "instrumento" para tratar da relação entre direito material e processual que, segundo ele, tem gerado frutos perversos. (CALMON DE PASSOS, 2001, p. 55-67). Em outra obra, afirma o autor: "A relação entre o processo de produção do Direito e o direito produzido, seja como enunciado, seja como decisão (dizer o Direito e aplicar o Direito) não é de caráter instrumental, meio-fim, sim de natureza substancial, integrativa. O Direito é o que dele faz o processo de sua produção. Isto nos adverte de que nunca é algo dado, pronto, preestabelecido ou pré-produzido, cuja aplicação é possível, mediante simples utilização de determinadas técnicas e instrumentos, com segura previsão das conseqüências". (CALMON DE PASSOS, 2003, p. 68).

${ }^{15}$ Conforme Calamandrei, esse conceito de ação demonstra a prevalência do interesse individual e se adapta à concepção liberal do Estado e à idéia de que o fim do processo seja apenas de tutelar direitos subjetivos. (CALAMANDREI, 1961, p. 139). 
relação entre o juiz e as partes: uma relação de direito público diferente da relação substancial litigiosa (DINAMARCO, 1971, p. 24). O reconhecimento da autonomia do direito de ação completou-se com Adolf Wach (CHIOVENDA, 2004, v. 1, p. 39).

A partir da autonomia do direito de ação, especialmente duas doutrinas passam a explicar o direito de ação: a teoria abstrata e a teoria concreta. Para esta última - criada por Adolf Wach - a ação é um direito autônomo e concreto. Dirige-se contra o Estado que tem a obrigação de prestá-la e, também, contra o adversário em face de quem ela deve ser outorgada. Dessa forma, do primeiro exige-se a proteção jurídica e do segundo, a sujeição (MESQUITA, 1975, p. 45). ${ }^{16}$ O direito de ação, para a teoria abstrata, é um direito abstrato e genérico. Ela "dá por admitido um ponto fundamental: o de que existe um direito a agir em juízo ainda quando não se tenha um direito subjetivo válido" (COUTURE, 1946, p. 36-8). Tal evolução do entendimento a respeito do direito de ação "invadiu a Itália ao raiar do século XX, por intermédio da aula magna de Chiovenda em 1903, e tomou a atenção dos processualistas italianos, que a ela dedicaram o melhor de seus esforços” (ARAGÃO, 2002, p. 10). ${ }^{17}$

Em 1938, surge o trabalho de Calamandrei: "La relatividad del concepto de acción” cuja finalidade, segundo o autor, era demonstrar que as várias teorias a respeito do conceito de ação possuem justificação histórica e política e estavam ligadas às diversas concepções sobre a relação entre cidadão e estado, não podendo ser consideradas em si mesmas como absolutamente verdadeiras ou falsas (CALAMANDREI, 1961, p. 138-139). Esse relativismo de Calamandrei é visto por José Ignácio Botelho de Mesquita (1975, p. 9) como verdadeiro ceticismo dirigido "muito mais aos rumos políticos pelos quais se orientava a Europa de então, do que propriamente à teoria da ação”.

No Brasil, as discussões que revolucionavam os estudos de processo em outros países não envolviam os processualistas (CINTRA; GRINOVER; DINAMARCO, 2003, p. 126). ${ }^{18}$ A autonomia do direito de ação passou a ser aceita, no Brasil,

${ }^{16}$ José Ignácio Botelho de Mesquita (1975) afirma ainda que embora a teoria do direito concreto de ação tenha alcançado larga repercussão na Alemanha, alguns (Hellwig e Goldschmidt) divergiam de Wach, pois não aceitavam que "a ação se dirige contra o Estado e também contra o réu”, já que o sujeito passivo seria apenas o Estado.

${ }^{17}$ Para Chiovenda, a ação é direito potestativo: "A ação é um poder que nos assiste em face do adversário em relação a quem se produz o efeito jurídico da atuação da lei. O adversário não é obrigado a coisa nenhuma diante desse poder: simplesmente lhe está sujeito". (CHIOVENDA, 2002. v. 1, p. 37-8).

${ }^{18}$ Diz Ada Pellegrini Grinover (1973. p. 65): "tardou no Brasil, a renovação científica do 
segundo José Ignácio Botelho de Mesquita (1975, p. 48), por volta da década de 30 do século passado. Não houve, aqui, tempo suficiente para que a teoria do direito concreto de ação tivesse grande repercussão. "Transpõe-se, em aproximadamente dez anos um período que, na Europa, estendeu-se por quase um século, pois da autonomia do direito de ação passou-se para a teoria de Liebman”.

Liebman (1985, p. 152) distingue direito subjetivo substantivo e direito de ação . Este como direito de iniciativa e impulso que se dirige ao Estado "sem se destinar à obtenção de uma prestação deste". ${ }^{19} \mathrm{O}$ que afasta Liebman dos abstrativistas puros é a distinção que ele faz entre a ação como garantia constitucional e a ação processual. A primeira incondicionada (poder de agir em juízo), atribuída a todos, e a segunda condicionada à presença de requisitos de existência: as condições da ação cuja falta faz o autor "carecedor de ação". Inicialmente, Liebman referia-se a três condições da ação: possibilidade jurídica do pedido, interesse de agir e legitimidade para agir. $\mathrm{Na} 3^{\circ}$ e $4^{\circ}$ edição de seu "Manual de direito processual civil”, ele passa a encarar os casos não admitidos abstratamente pela lei como ausência do interesse de agir excluindo, assim, a possibilidade jurídica do pedido (LIEBMAN, 1985, p. 161). ${ }^{20}$ A legislação processual brasileira adotou a teoria liebmaniana na forma original (Art. 267, VI CPC).

As condições da ação requerem estudo específico. Não é esse o objetivo deste trabalho. A importância da referência restringe-se ao necessário à compreensão da tese exposta sobre o direito de ação, a partir da Constituição Federal.

direito processual. Os tratadistas ressentiam-se da influência dos autores portugueses, igualmente impermeáveis, por muito tempo, aos novos conceitos formulados pela processualística moderna. No tocante à natureza do direito de ação, os autores pátrios não se distanciavam do conceito clássico configurando a ação como parte integrante da relação jurídica privada”.

${ }^{19}$ Em nota de rodapé à página 352 da sua obra Execução civil, Dinamarco faz algumas observações sobre o entendimento de Liebman a respeito do direito de ação como um direito subjetivo diferente daqueles do direito substancial, porque dirigido ao Estado, sem se destinar à obtenção de uma prestação deste. Segundo Dinamarco, há neste conceito uma aparente contradição parecendo lícito crer que "na realidade, o Mestre estaria verdadeiramente conceituando a ação como poder, não como direito". (DINAMARCO, 2000, p. 352).

${ }^{20}$ Nota incluída pelo tradutor à página 161 . Vários processualistas brasileiros seguem a distinção feita por Liebman, entre eles: Armelin (1979) e Arruda Alvim (2003, v. 1). Contrariamente: Grinover (1973). 


\section{ARTIGO 5aㅡ, XXXV DA CONSTITUIÇÃO FEDERAL: PRINCÍPIO PREDOMINANTEMENTE PROCESSUAL}

A Constituição - como todo o ordenamento jurídico do Estado Democrático de Direito - é um sistema normativo de regras e princípios no qual os procedimentos adquirem importância fundamental e podem ser definidos, conforme Willis Santiago Guerra Filho (2002, p. 19-20), como "séries de atos ordenados com a finalidade de propiciar a solução de questões cuja dificuldade e/ou importância requer uma extensão temporal, para que se considerem aspectos e implicações possíveis". Entre tais procedimentos, destacam-se aqueles que envolvem participação e influência de vários sujeitos na formação do ato final decisório os quais recebem, segundo o autor, a denominação técnica de "processo".

O que se objetiva enfatizar não é apenas a origem constitucional dos institutos processuais, mas o próprio entendimento que se possa ter do processo e do procedimento a partir da concepção de Willis Santiago Guerra Filho (2002, p. 27-31), o qual assevera: a "Constituição possui a natureza (também) de lei processual, assim como institutos fundamentais do direito processual possuem estatuto constitucional e, logo, são (também) de natureza material”. Dessa forma, o direito processual não é apenas um simples ramo da árvore jurídica, mas uma dimensão do Direito.

Ainda conforme Willis Santiago Guerra Filho (2002, p. 28), materiais são as normas quando fornecem parâmetros para realizar o controle e ordenação da conduta intersubjetiva pelo Direito, e processuais, quando se ocupam com a "determinação das condições para que esses parâmetros venham a ser aplicados concretamente”.

Dessa forma, é possível afirmar que o direito de ação - fundamentado constitucionalmente no artigo $5^{\mathrm{a}}, \mathrm{XXXV}$ da Constituição, ${ }^{21}$ constitui-se num princípio, predominantemente, processual. A utilização do advérbio carece de explicação. O princípio é processual, pois se dirige ao legislador e ao juiz. Ao primeiro porque a norma que produzir não poderá promover a referida exclusão. Ao juiz, porque, sendo a sentença também norma jurídica, não poderá deixar de apreciar lesão ou ameaça a direito. Como não se ocupa diretamente em realizar o controle e ordenação da conduta intersubjetiva, trata-se de norma processual. Todavia há também uma dimensão material que se extrai do referido inciso, ao estabelecer-se o dever de apreciação, pelo Judiciário, de lesão ou ameaça a direito

${ }^{21}$ Artigo $5^{\text {a }}$,XXXV/CF: “a lei não excluirá da apreciação do Poder Judiciário lesão ou ameaça a direito". 
que não poderá ser excluído por norma alguma (legislada ou não). $\mathrm{O}$ direito correspondente - atribuído pelo referido inciso - é o direito ao processo. Não é apenas o direito de pedir ou o direito de acionar o Estado. É o direito ao procedimento que propiciará, efetiva e adequadamente, a apreciação da lesão ou ameaça a direito alegada com participação e influência de vários sujeitos na formação do ato final decisório (Willis Santiago). Portanto, tecnicamente, tratase de direito ao processo. ${ }^{22}$

Essa dimensão material apontada acima não é estabelecida isoladamente, ou seja, com base apenas no inciso sob estudo. Há outros parâmetros que se encontram em outros princípios (valores) constitucionais, entre os quais destaca-se aquele constante no inciso LIV do mesmo Artigo 5a: "ninguém será privado da liberdade ou de seus bens sem o devido processo legal”. O judiciário tem o dever de apreciar a lesão ou ameaça a direito, mas o fará respeitando as normas processuais que serão estabelecidas de acordo com o sistema constitucional.

Além do princípio do devido processo legal, diversos são os princípios constitucionais que devem ser considerados para que se estabeleça o entendimento daquele direito predominantemente processual que é o direito ao processo expresso no Artigo 5 $5^{a}, X X X V$, entre os quais: a necessidade de respeito ao princípio: da

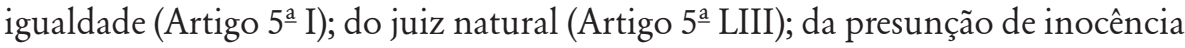
(Artigo 5 $\left.5^{\underline{a}} \mathrm{LV}\right)$; do contraditório e da ampla defesa (Artigo 5 $\left.5^{\underline{a}} \mathrm{LVI}\right)$; do tempo razoável do processo (Artigo $5^{\underline{a}}$ LXXVIII). Não apenas no Artigo $5^{\frac{a}{a}}$ podem ser encontrados tais princípios. O juiz que aprecia a lesão ou a ameaça a direito é o juiz que também se conforma com o texto constitucional. Ou seja, deverá ser o juiz preparado e em constante aperfeiçoamento, cuja capacidade possa ser aferida através de "critérios objetivos de produtividade, presteza no exercício da jurisdição e pela freqüência e aproveitamento em cursos oficiais ou reconhecidos de aperfeiçoamento" (Artigo 93, I, c). Outro princípio a ser observado é o que se refere à necessidade de fundamentação das decisões (Artigo 93, IX).

Todavia, o principal vetor (parâmetro) presente no texto constitucional é aquele que estabelece sua fórmula política. E fórmula política de uma constituição é "o elemento caracterizador da Constituição, principal vetor de orientação para a interpretação de suas normas e, através delas, de todo o ordenamento jurídico".

${ }^{22} \mathrm{O}$ que se expôs aproxima-se da afirmação de Cândido Rangel Dinamarco: "hoje facilmente se compreende que todo poder se exerce mediante um procedimento, caracterizando-se este como processo desde que seja feito em contraditório". (DINAMARCO, 2002, p. 152). 
De acordo com Willis Santiago Guerra Filho (2005, p. 16-7)23 , a fórmula política na Constituição Brasileira de 1988 está expressa no seu artigo primeiro.

O que se expôs aqui sobre o denominado direito de ação está, portanto, fundamentado na concepção da constituição e do Direito centrada na idéia de processo que, segundo o entendimento de Willis Santiago Guerra Filho (2001b, p. 79-80) mostra-se como uma superação de noções anteriores - formal e material - relacionadas com outros modelos de estado e constituição. A primeira delas, coerente com uma época na qual o desejo era pôr fim a formas de dominação feudal e absolutista e a principal função jurídica era a "garantia formal do respeito à posição social dos indivíduos e sua possibilidade de livre atuação". Com a falência desse modelo, pela sua incapacidade de atender aos reclamos sociais, o Direito serviu para materializar exigências sociais. Todavia, esse modelo também decai.

É possível afirmar que a primeira concepção apresentada acima corresponde ao estado liberal e a segunda, ao estado social. Num estado democrático de direito, porém, considerado como a superação daqueles, o que se deve fazer é estabelecer procedimentos para que se chegue a decisões possibilitando, assim, que as mesmas sejam acatadas. Porém, tais procedimentos devem ser estabelecidos de acordo com os valores presentes, mormente no texto constitucional. Nesse aspecto, o entendimento apresentado neste trabalho, como também aqueles defendidos por Canotilho, Alexy e Willis Santiago Guerra Filho, se afasta das doutrinas procedimentais puras. A idéia defendida coaduna-se ainda com as que foram apresentadas no início do trabalho como uma "terceira via", ou um "caminho do meio" entre positivismo e jusnaturalismo. Aproxima-se também da tese de Calamandrei sobre os diversos conceitos formulados a respeito da ação. ${ }^{24}$

${ }^{23} \mathrm{O}$ autor, nessa afirmação segue a orientação de Pablo Lucas Verdu em Curso de derecho político (1986, p. 532). Em outra obra, Willis Santiago Guerra Filho cita a definição de Lucas Verdú: "a fórmula política de uma Constituição é a expressão ideológica que organiza a convivência política em uma estrutura social”. (GUERRA FILHO, 2001, p. 99).

${ }^{24}$ Conforme já afirmado, para Calamandrei, sob os diversos conceitos formulados a respeito da ação há um só problema: o das relações entre cidadão e Estado. Acrescentase o entendimento de Luiz Fernando Belinetti: admitida a concepção autônoma da ação, nenhuma das teorias que procura explicá-la é intrinsecamente correta ou incorreta. "Sua concretude ou abstraimento dependerá exclusivamente da opção política que se faça para a fixação do seu conceito. A vinculação do direito de ação com o direito subjetivo material não é um dado que possa ter uma única solução, posto que esta dependerá da opção que se faça em cada ordenamento jurídico relativamente aos direitos das pessoas frente ao órgão jurisdicional, e mais 
A referência a diversos princípios (valores) na constituição ressalta a possibilidade de existência de conflito entre eles e, portanto, de necessidade de conciliação, o que remete ao princípio da proporcionalidade - e seus elementos exigibilidade, adequação e proporcionalidade em sentido estrito - instaurando encadeamentos novos e válidos de normas para atender a necessidades de mudanças e adaptações do sistema normativo.

\section{CONCLUSÃO}

Após todo o exposto, resta apenas afirmar que o direito de ação como direito ao processo, da forma como foi apresentado, permite novos estudos e novas análises adequadas ao atual Estado democrático de direito abrindo caminho para a superação da crise identificada no início deste trabalho.

\section{REFERÊNCIAS}

ALEXY, Robert. El concepto e y la validez del derecho. Trad. Jorge M. Seña. 2. ed. Barcelona: Gedisa, 2004.

ARAGÃO, Egas Dirceu Moniz de. Hobbes, Montesquieu e a teoria da ação. Revista de Processo, São Paulo, v. 108, p. 10-22, out/dez. 2002.

BARROSO, Luís Roberto. O direito constitucional e a efetividade de suas normas: Limites e possibilidades da constituição brasileira. 7. ed. Rio de Janeiro: Renovar, 2003.

BELINETTI, Luiz Fernando. Sentença civil: perspectivas conceituais no ordenamento jurídico brasileiro. São Paulo: Editora Revista dos Tribunais, 1994.

. Ação e condições da ação. Revista de Processo, São Paulo, v. 96, p. 260266, out/dez. 1999.

BERCOVICI, Gilberto. Desigualdades regionais, estado e constituição. São Paulo: Max Limonad, 2003.

BOBBIO. Norberto. O positivismo jurídico: lições de filosofia do direito. Trad. e notas de Márcio Pugliesi; Edson Bini; Carlos E. Rodrigues. São Paulo: Ícone, 1995.

BONAVIDES, Paulo. Curso de direito constitucional. 14. ed. São Paulo: Malheiros, 2004.

especificamente ao tipo de resposta que o Estado tem o dever de fornecer àqueles que postulam a tutela jurisdicional”. (BELINETTI, 1999, p. 2). 
. Do estado liberal ao estado social. 7. ed. São Paulo: Malheiros, 2004. 230 p.

CALAMANDREI, Piero. La relatividad del concepto de acción. In: Estudios sobre el proceso civil. Trad. Santiago Melendo. Bueno Aires: Editorial Bibliográfica Argentina, 1961.

CANOTILHO. José Joaquim Gomes. Tópicos de um curso de mestrado sobre direitos fundamentais, procedimento, processo e organização. Boletim da Faculdade de Direito da Universidade de Coimbra, v. 66, p. 151-201, 1990.

CHIOVENDA, Giuseppe. Instituições de direito processual civil. Trad. Paolo Capitanio. 3. ed. Campinas: Bookseller, 2002. 2v.

CINTRA, Antonio Carlos Araújo; GRINOVER, Ada Pellegrini; DINAMARCO, Cândido Rangel. Teoria geral do processo. 19. ed. São Paulo: Malheiros, 2003.

CORDEIRO, Antonio Menezes. Prefácio. In: CANARIS, Claus Wilhelm. Pensamento sistemático e conceito de sistema na ciência do direito. Intr. e trad. Antonio Menezes Cordeiro 3. ed. Lisboa: Fundação Calouste Gulbenkian, 2002.

COUTURE, Eduardo J. Fundamentos do direito processual civil. Trad. Rubens Gomes de Souza. São Paulo: Saraiva, 1946.

DINAMARCO, Cândido Rangel. Instituições de direito processual civil. 4. ed. São Paulo: Malheiros, 2002. 2v.

. Reflexões sobre direito e processo. Revista dos Tribunais, São Paulo, v. 432, p. 23-38, out. 1971.

GRINOVER, Ada Pellegrini. O direito de ação. Revista dos Tribunais, São Paulo, v. 451, p. 24-31, maio 1973.

GUERRA FILHO, Willis Santiago. Processo constitucional e direitos fundamentais. 4.ed. São Paulo: RCS Editora, 2005.

. Teoria processual da constituição. 2. ed. São Paulo: Celso Bastos Editor, 2002.

A filosofia do direito aplicada ao direito processual e à teoria da constituição. São Paulo: Atlas, 2001.

. Da interpretação especificamente constitucional. Revista de Informação Legislativa, Brasília, v. 128, p. 256-259, out./dez. 1995. 
. Teoria da jurisdição: nota sobre uma nova disciplina. Revista de Processo, São Paulo, v. 59, p. 231-3, jul/set. 1990.

HABERMAS, Jürgen. Justiça e legislação: sobre o papel e a legitimidade da jurisdição constitucional. In: Direito e democracia - entre facticidade e validade. Trad. de Flávio Beno Siebeneichler. 2. ed. Rio de janeiro: Tempo Brasileiro, 2003. v. 1 , p. 297-354.

KAUFMANN, Arthur. Filosofia do direito. Trad. Antonio Ulisses Cortês. Lisboa: Fundação Calouste Gulbenkian, 2004.

LIEBMAN, Enrico Tullio. Manual de direito processual civil. 2. ed. Trad. e notas Cândido Rangel Dinamarco. Rio de Janeiro: Forense, 1985.

LUHMANN, Niklas. A posição dos tribunais no sistema jurídico. Trad. Peter Naumann. Ajuris, Porto Alegre, v. 49, p. 150-68, jul. 1990.

MESQUITA. José Ignácio Botelho de. Da ação civil. São Paulo: Editora Revista dos Tribunais, 1975.

STRECK, Lênio Luiz. Jurisdição constitucional e hermenêutica. Uma nova crítica do direito. 2. ed. Rio de Janeiro: Forense, 2004.

VERDÚ, Pablo Lucas. Curso de derecho político. 3. ed. rev. Madrid: Tecnos, 1986.

VERDÚ, Pablo Lucas; CUEVA, Pablo Lucas Murillo de la. Manual de derecho político. 3. ed. Madrid: Tecnos, 1994. v. 1. 